\title{
Utility of Submucosal Turbinoplasty for the Treatment of Chronic Nasal Obstruction
}

\author{
Novak Vukoje ${ }^{1}$, Miroslav Cvetinov ${ }^{2 *}$ and Jon Garito ${ }^{3}$ \\ ${ }^{1}$ ENT office "dr Vukoje", Petrovaradin, Serbia \\ ${ }^{2}$ Ph.D, Faculty of Sciences, University of Novi Sad, Republic of Serbia \\ ${ }^{3}$ Ph.D, Oceanside, New York, United States of America
}

Submission: October 02, 2017; Published: October 17, 2017

*Corresponding author: Miroslav Cvetinov, Ph. D, Faculty of Sciences, University of Novi Sad, Republic of Serbia, Tel: +381(63)513676;

Email: miroslav.cvetinov@df.uns.ac.rs

\begin{abstract}
Introduction: Surgery of inferior turbinates is a divisive subject. Surgical management includes functional and invasive procedures. There is currently no consensus on the most effective technique. Radiofrequency ablation is one of numerous interventions available for the treatment of nasal opstruction secondary to inferior turbinate hypertrophy. The goals of inferior turbinate surgery include volume reduction, reduction in nasal obstruction, and maintenance of nasal function while minimizing complications. Two hundred patients, who had nasal obstruction due to inferior turbinate hypertrophy and obstinate to medical therapy, underwent submucosal turbinoplasty procedure in the ENT office "dr Vukoje" in Petrovaradin, Republic of Serbia, from January 2012 to December 2015. The diagnosis was based by anamnesis, clinical examination, nasal endoscopy, ephedrine test, palpation mucosis test and imaging. We used radiofrequency device Ellman Sugitron dual 4.0 Mhz, (inventor Dr Jon C. Garito, PhD) unit with power of 70 watts of radio wave emission in monopolar mode for 10-15 seconds. Postoperative follow-up was scheduled at 1,3 and 6 months. Among 200 patients 158 patients (79\%) were completely relieved of symptoms, 9 patients (4.5\%) partialy relieved and 33 patients $(16.5 \%)$ showed no improvement based on both subjective and objective parameters.
\end{abstract}

Conclusion: Due to its simplicity, minimally invasive nature and efficiency, the radiofrequency tissue ablation procedure is one amongst the best apt surgical option for management of inferior turbinate hypertrophy and the current study added credit to its efficiency once again.

Keywords: Radiofrequency; Nasal obstruction; Inferior turbinate hypertrophy

\section{Introduction}

Enlarged lower nasal shells are the second most common cause of chronic nasal obstruction, which produces deviation of the nasal septum [1-12]. Worldwide, nearly two billion people have a chronic nasal congestion caused by this etiology. Mucosal hypertrophy can affect any part of the turbinates: its anterior part, the middle or of the last third, or simply the whole length. The thickness of the mucous membrane of the nasal conchae varies: in the front third is $1.15 \mathrm{~mm}$, in the central third $0.75 \mathrm{~mm}$ and the last third $0.65 \mathrm{~mm}$. Hypertrophy of the nasal turbinates can be caused by mucous membranes hyperplasia, protrusion of the bone part and by combination of both factors.

It is usually two-sided, although there is one-sided compensatory hypertrophy most commonly on the opposite side of the deviation of the nasal septum. Their role in respiratory physiology is large and they participate in moisturizing, heating and purifying the air. Also, we should not neglect the importance of these structures in olfaction and phonation. The cycle of alternating congestion on one side and the other side of the nose, which takes place at 2-6 hours, indicates that both nostrils are not equally passable. The dysfunction of nasal turbinates is primary consideration with the new onset of balancing rhinitis, which is manifested by blocked nose on the sleeping side. About $25-30 \%$ of the total surface of the nasal mucosa is present on the lower part of turbinates (Figure 1).

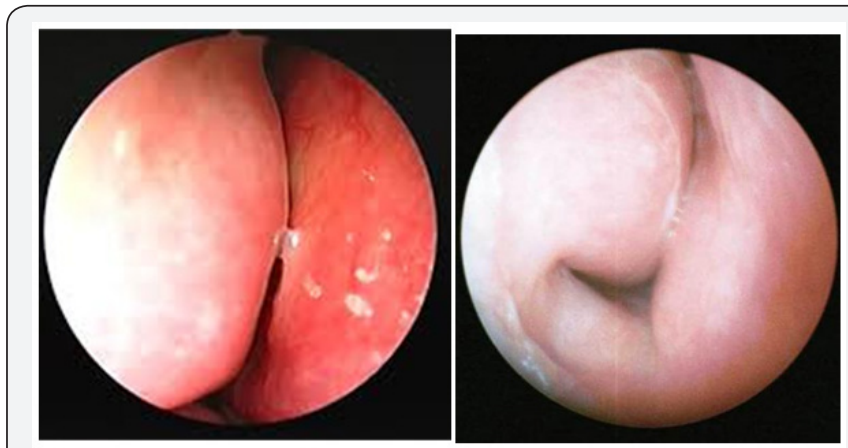

Figure 1: Enlarged inferior nasal turbinates / Stage II and III by Friedman. 
The literature mentions numerous causes of hyperplasia, such as allergic, vasomotor, hormonal, idiopathic, medication induced, infectious rhinitis, etc. Hyperactive mucous membrane and onesided rhinitis of «build-up» turbinates is often seen in body builders who use anabolic steroids and people who often snort drugs. Also, the group of rhinopathies are not to be omitted. As there are bone, mucous and bone-mucous hyperplasia of the conchae, it is very important to determine which one is in question. To determine whether hyperplasia is mucous or bony, the so-called ephedrine test is employed. Moreover, as a consequence of this test, the visibility of the last third of the conchae improves.

The palpation test with cotton swab can be useful in the assessment of the «soft» and «rigid» hyperplasia of the conchae. If the mucous membrane is soft and deflecting on touch, it indicates the mucosal hypertrophy. As a consequence of this pathology, symptoms may be expressed in the form of nasal congestion, rhinorrhea, post-nasal drips, sneezing, rhinogenic headaches, noisy sleep, oscillations in the odor, etc. Diagnosis is made by anamnesis, clinical ENT findings, anterior and posterior, rhinoscopy, fiberendoscopy, mucociliary clearance, rhinomanometry, radiography of paranasal sinuses, etc. In the case of these conditions, conservative medication therapy is usually applied first, and if improvement goals are not met in few months we should consider surgical modality. Turbinate surgery dates back to 1890 (Jones). In 1900, Holm described the stages of enlargement of turbinates and surgical experiences of 1500 operative cases of conchotomy - complete removal of the lower turbinates [11] (Figure 2).

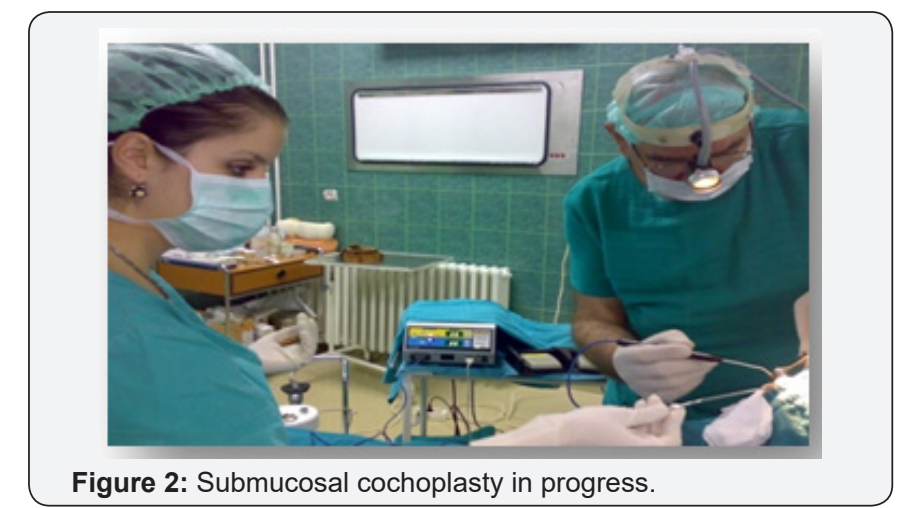

Due to complications like atrophic rhinitis and empty nose syndrome, the operations of this type are almost abandoned. Moreover, these surgical procedures require total anesthesia with a risk of bleeding and wearing a tampon in the nose for several days. Today there are many modern surgical techniques that are more or less successful in solving this pathology. Traditional cold technique, cryotherapy, electrocauterisation, laser, coblator, high-frequency radio waves, microdebrider and other are possible options in the treatment of «chronic nasal congestion» caused by mucosal hyperplasia of lower turbinates [2,3]. The choice of method and technique is not straightforward because of the existence of arguments for and against each of them.

Much more important is whether surgery is really the right option to treat this pathology. With the aim of preserving the mucous membrane, improvements in subjective problems and the avoidance of complications, less invasive techniques have advantage. One of them is the submucosal conchoplasty which is performed with high-frequency radio waves with a specially designed electrode on a permanent swelling of the submucosal tissue that is mainly responsible for this pathology. In most cases, only one single session is sufficient for the immediate «unblocking» of the nose. Some incidences that can be present in the first postoperative week are gradually and spontaneously eliminated. In case of recurrence it's always possible to repeat the procedure. After this intervention there is no need for placement of nasal tampon for nasal hemorrhages.

The first intervention on enlarged turbinates with radiofrequency ablation in Serbia was done by Dr. Vukoje Novak at the ENT Department at the Military Hospital Novi Sad in 2002. Indications for radiowave therapy are:

a) Hyperplastic mucous membrane of turbinates that causes chronic nasal obstruction that is not responding to medical therapy.

b) Turbinates that are physically blocking nasal valve.

c) When there are problems in aeration and draining of the sinuses.

d) In sleep apnea and snoring.

e) In difficulties of application of CPAP Device.

f) In FESS surgery (to provide access to the osteum)

g) In rhinogenic headaches and so on.

The goal of work was to present our results of surgical treatment of chronic nasal obstruction caused by hyperplasia of nasal mucosa of the lower turbinates by applying high-frequency waves.

\section{Material and Methods}

In the period from January 2012 to December 2015, the author operated 200 patients (360 lower turbinates) aged 16 to 64 years due to a nasal congestion caused by hyperplasia of the mucous membranes of the lower turbinates. The 160 patients were treated on both sides and 40 with one-sided conchoplastics. On all operated patients we have previously performed an endoscopic examination of the nose, an allergy test, an ephedrine test, a palpation test with cotton swab, and if necessary, a rtg PNS. A single number of patients had a rhinomanometric examination. Nasal shells were classified by grade of enlargement (Friedman grading system) at stage II or III [10]. Under stage III, it is understood when the lower shells completely covers the space in the nasal cavity.

For all patients, we have already prescribed medicament therapy (antihistamines, intranasal steroids, sea salt-based sprays, etc.) that didn't yield satisfactory results. Surgical interventions were made by the aid of Ellman Sugitron 4.0 MHz device using monopolar mode in the specialist ENT office «Dr Vukoje» in Petrovaradin. The patients were operated in a local anesthesia that included spraying with $10 \%$ xylocaine spray and additional infiltration of $2 \mathrm{ml}$ of $1 \%$ 
xylocain in the lower turbinates. During the procedures we have been guided by the following:

a. The choice of the active electrode.

b. Power output

c. Type of waves

d. Time of application

e. Frequency

The radial wave electrode is positioned submucosal parallel to the bone of the turbinates to the point where it produces a micro thermal lesion with adjusted parameters and a time interval of 1015 seconds. The number of lesions depends on the thickness of the mucous membrane and the size of the turbinates. In this regard, special care is taken not to mend the mucous membrane periosteum or bone of the same. The patient left the clinic 30 minutes after of intervention with the advice not to blow up the nose for the next three weeks and cleaning of nose to be done with the saline solutions or solution of sea salt. In the case of an allergic genesis of hyperplasia, additional therapy is included. Control examination is conducted after one, three and six months after surgery.

Results

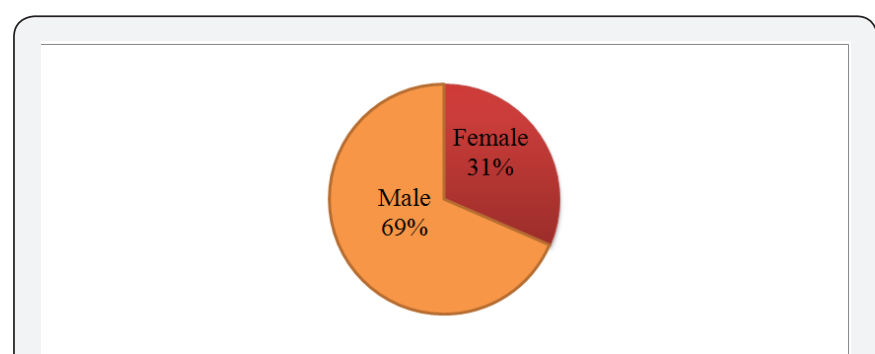

Figure 3: Distribution of patients by sex.

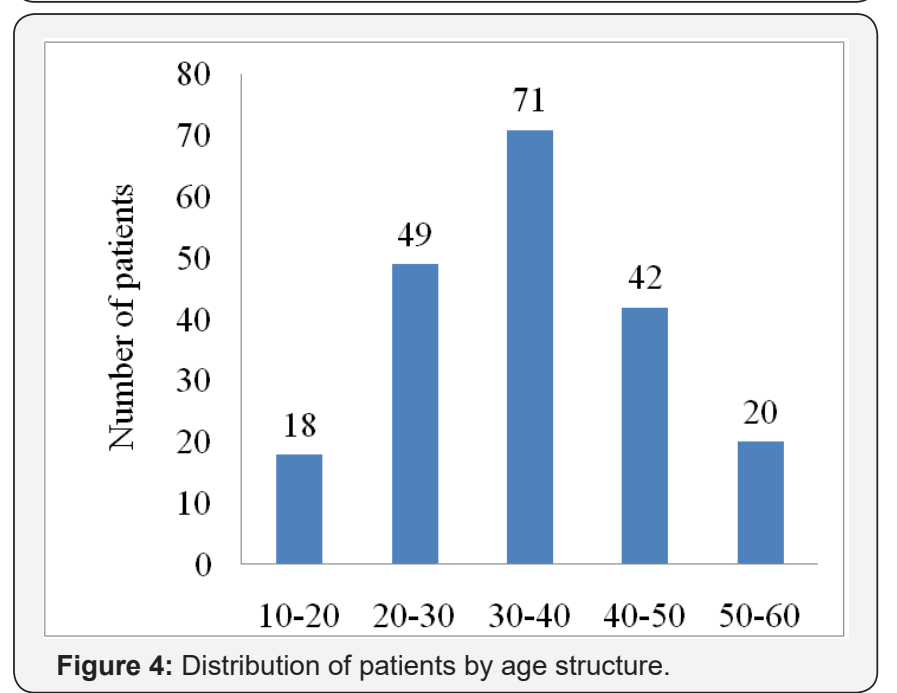

All patients complained of primary disorders in the form of chronic nasal congestion accompanied by other symptoms caused by hypertrophy of the mucous membranes of the lower turbinates. Of the 200 patients, 138 were male and 62 female and this ratio was 2.2: 1 in favor of a stronger sex (Figure 3). With respect to age, the population of 30-40 years of age is the most dominant. The youngest patient was 12 and the oldest 59 (Figure 4). The cause of hyperplasia of the lower nasal turbinates was allergic rhinitis in 62 patients, medication rhinitis in 44 patients, idiopathic rhinitis in 38 patients, vasomotor rhinitis in 35 , and chronic rhino-sinusitis in 21 cases. Postoperative results were analyzed based on the questionnaire - VAS (visual analogue scale) and VPS (verbal selfexamination) which includes: breathing through the nose during the day and during the night, runny nose, drooling of the secretion down the throat, improvement of the odor threshold, intensity of loud sleeping, headaches, periods without using nasal drops, etc.

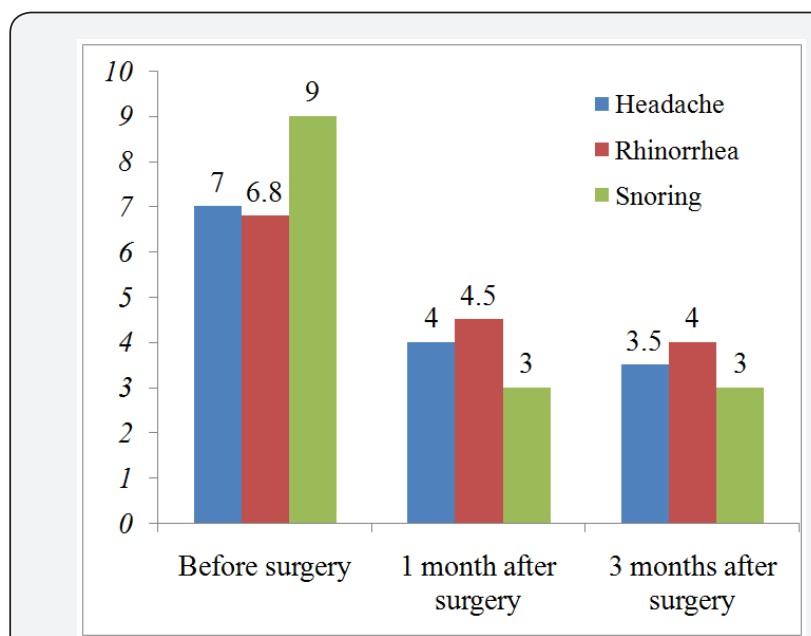

Figure 5: VAS- subjective assessment of symptoms: headaches, rhinorrhoea, snoring-before and after surgery.

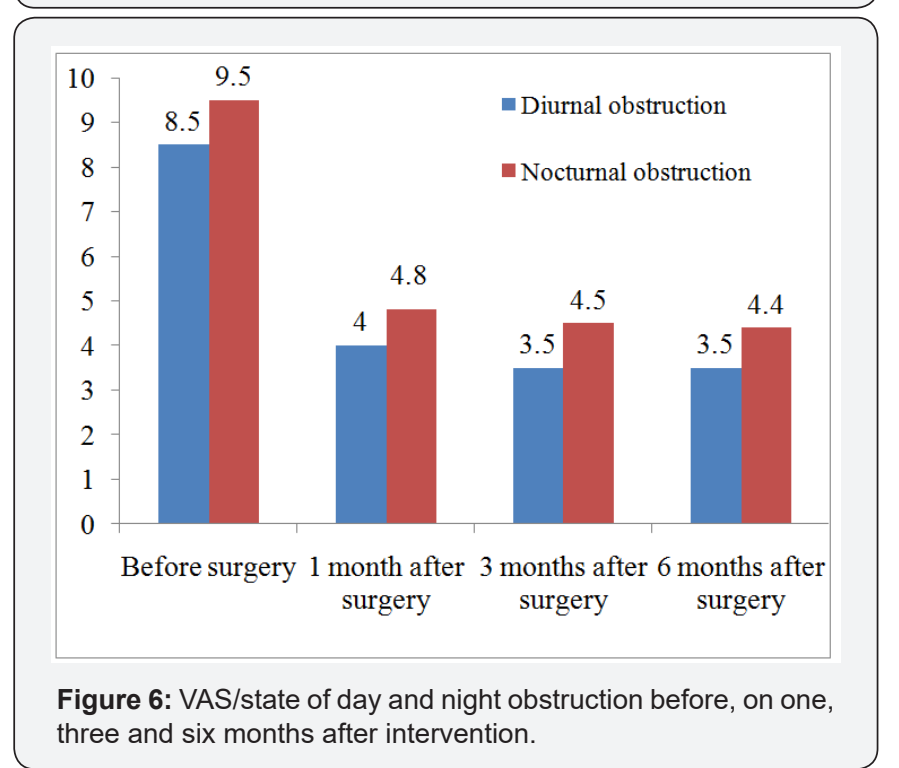

The assessment of the success of this operation was done in the first, third and sixth month of the intervention based on objective (endoscopic evaluation of the lower shells of nose) and the subjective parameters (VAS and VPS: satisfied, partially satisfied and dissatisfied). The results were compared before and after surgery (Figures $5 \& 6$ ). In the first week after the intervention, $90 \%$ of patients complained of worsening of the symptoms, which is in agreement with other authors $[4,5,12]$. These are most commonly: 


\section{Global Journal of Otolaryngology}

nasal congestion, rhinorrhoea, mild local pain, slight bleeding, stuffy nose etc. Usually at the beginning of the second week, the symptoms are gradually regressed, so that at the end of the first post-operative month $80 \%$ of patients begins to have significant reduction of symptoms, especially nasal obstruction.

Most of those who had surgery stated that they were satisfied with the regression of these symptoms in the following months after the intervention yet, the leading symptoms for which majority of patients sought help were snoring and nasal obstruction, and diminishing of their intensity were recorded at the end of the fourth week. The Figure 6 shows that the symptoms of difficulty breathing in the nose during the following months have been greatly improved, both during day and during sleep. The majority of the patients stated that there was no longer a need to use nasal drops, and that they are satisfied with the performed procedure. At the end of the sixth month, 158 patients (79\%) were satisfied with the treatment, 9 patients $(4.5 \%)$ partially, while 33 patients $(16.5 \%)$ did not make any improvements. The VAS was used is in the range of $0-10$, where 0 means no trouble and 10 an extreme expression of interference.

\section{Discussion}

The hypertrophy of mucous membranes of the lower turbinates is the second most important cause of chronic nasal obstruction. The surgical procedures of enlarged turbinates have been a topic for over 100 years. Today there are numerous operating techniques in volume reduction of the lower turbinates. In addition, there is no consensus about what procedure is the best in treating this pathology. An ideal intervention would be one that would preserve the physiological functions of the nasal shells such as a regulation of moisturizing, heating and purifying inhaled air without complications $[1,3,9]$. Numerous studies that deal with the effectiveness of radiowave surgery in the reduction of nasal obstruction caused by the hyperplasia of the mucous membranes of the lower turbinates indicate that this technique has a number of advantages over others such as: conventional cold technique, electrocauters, laser, cryotherapy, etc. [1-3,5,6,10].

The goal of radiofrequency ablation, i.e. submucosal conchoplasty, is maximal reduction of volume of turbinates with minimal complications in order to ease and relieve nasal congestion in long term and to preserve the mucous membrane. With this operation we achieve the expansion of the nasal space, reduced resistance in the airways, reduction of nasal and postnasal secretion, better aeration and drainage of the sinus, calm sleep, etc. [1,5-8]. The reduction of turbinates is carried out through a microthermal lesions and burns at the site of application of the electrode (submucosal tissue) which is followed by necrosis, fibrosis and scar formation. The final result is the adherence between septum and all of nasal mucosa and the reduction of blood flow, the reduction in turbinate tissue volume and at the same time the enlargement of the airway passage. Effectiveness of this procedure depend on degree and location of hyperplasia, patient age and operation technique. We consider that the success of this intervention is undermined by: i. Poor selection of patients,

ii. Inadequate knowledge of technology

iii. Incorrect placement of the electrode

iv. Mucosal necrosis as a result of too much energy

v. Uneven indurations of mucous membranes by anesthetics

Our results are slightly worse in comparison to S.B. Amarnatha and Arfin Aloora [3] published in 2014, where out of 100 operated patients the symptoms of nasal obstruction are completely resolved in 92 by the application of this technique. According to their opinion and other numerous studies $[6,7,8,12]$, efficiency of radio waves in the treatment of this pathology is undisputed. Cavalieretar [7] and Cingietal [8] point out that the significant improvement of the symptoms are visible after the first post-operative month which is supported by our own findings. The mentioned authors state that they did not have any undesirable neither intra-operative nor postoperative complications (Table 1 ).

Table 1: Postoperative results.

\begin{tabular}{|c|c|c|c|}
\hline $\begin{array}{c}\text { Time after the } \\
\text { operation }\end{array}$ & One month & Three months & Six months \\
\hline $\begin{array}{c}\text { Satisfied } \\
\text { patients }\end{array}$ & $160(80 \%)$ & $158(79 \%)$ & $158(79 \%)$ \\
\hline $\begin{array}{c}\text { Partially } \\
\text { satisfied }\end{array}$ & $9(4.5 \%)$ & $9(4.5 \%)$ & $9(4.5 \%)$ \\
\hline Dissatisfied & $31(15.5 \%)$ & $33(16.5 \%)$ & $33(16.5 \%)$ \\
\hline
\end{tabular}

Complications [5,12] during these procedures do most likely manifest themselves as thermal mucosal damage, septum-conchae adhesions, necrosis of mucous membranes, atrophic rhinitis and etc. Generally the complications are direct damage of the mucosa due to application of large radiofrequency energy which require additional interventions. Knowledge of this technology, careful work, adjustment of radiowave energy according to the age of the patient and the thickness of the mucous membrane are important parameters that need to be considered [1,2]. Excessive damage of blood vessels and nerves underneath nasal mucosa could produce atrophic rhinitis regardless of the mucosal damage alone. Complications we encountered included four cases of the synechiae formation between the conchae and nasal septum. After additional treatment these were resolved successfully. Also, in seven cases, intervention in the caudal part of the ala of nose resulted in bleeding requiring a nasal tapenade [13].

\section{Conclusion}

Submucosal conchoplasty is a simple, safe and effective method in addressing nasal obstruction caused by the hyperplasia of the lower ala of nose. Pathology of enlarged nasal shells, degree of obstruction and location hyperplasia of the mucous membrane are key parameters to be taken into account. In addition, the choice of the active electrode, the adequately adjusted power of the device and the operator's experience can be crucial between good and bad results. Submucosal concoplasty do not disturb muco-chilliary clearance, do not damage the mucous membrane, relatively rapidly 
relieve nasal congestion, the side effects are negligent, and the complications are rare. Degree and the cause of hyperplasia, patient age and selection of operational technique may be of importance for final outcome of this procedure. The disadvantage of this surgery is that with the time that follows the interventions it loses its rating. The optimum results are up to five years, when it should be repeated.

\section{References}

1. Vukoje N (2015) Hrkanje i slip apneja-uzroci i lečenje, med. knjiga, izdavač Maxima graf. Petrovaradin (strana 151-154) 2015g

2. Vukoje $N$ (2008) Primena radiofrekventnih talasa u hirurgiji glave i vrata; Acta Med Sal 37(2): 137-142.

3. SB Amarnath, Arfin Aloor (2014) Role of radio frequency in the management of inferior turbinate hypertrophy. J of Evolution of Med and Dent Sci 57.

4. Salzano FA, Mora R, Dellepiane M, Zannisl, Salzano G, et al. (2009) Radiofrequency, highfrequency, and electrocautery treatments vs partial inferior turbinotomy: Microscopic and macroscopic effects on nasalmucosa. Arch Otoaryngol Head Neck Surg 135(8): 752-758.

5. Bhandarkar ND, Smith TL (2010) Outcomes of surgery for inferior turbinate hypertrophy. Curropin otolaryngol headneck surg 18: 49-53.

6. Parida PK, Santosh K, Ganesan S, Surinarayanan G, Saxena SK (2016) The efficacy of radiofrequency volumetric tissue reduction of hypertrophied inferior turbinate in allergic rhinitis. Indian journal of medical sciences 65: 269-277.

7. Cavaliere M, mottola G, lemma M (2005) Comparison of the effectiveness and safety of radiofrequency turbinoplasty and traditional surgical technique in treatment of inferior turbinate hypertrophy. Otolaryngol head neck surg 133:972-978.

8. Cingi C, ure B, Cakli H, Ozudogru E (2010) Microdebrider assisted versus radiofrequency assisted inferior turbinoplasty: A prospective study with objective and subjective outcome measures. Actaotolaryngolital 30: 138-143.

9. Paraya Assanasen, Panyalak Choochurn, Wish Banhiran, Chaweewan Bunnag (2014) Radiofrequency inferior turbinate reduction improves smell ability of patients with chronic rhinitis and inferior turbinate hypertrophy. Allergyrhinol 5: e12-16.

10. Batra PS, Seiden AM, Smith TL (2009) Surgical management of adult inferior turbinate hypertrophy: A systematic review of the evidence. Laryngoscope 119(9): 1819-1827.

11. Friedman M, Tanyeri H, lim, (1999) A safe, alternative technique for inferior turbinate reduction. Laryngoscope 109: 1834-1837.

12. Elizabeth Whitaker (2007) Rhinoplasty, Turbinate Reduction, e Medicine, strana 1-16.

13. Passal D (2003) Treatment of Inferior Turbinate Hypertrophy. Ann Otol Rhinol Laryngol 112(8): 683-688.

Your next submission with Juniper Publishers will reach you the below assets

- Quality Editorial service

- Swift Peer Review

- Reprints availability

- E-prints Service

- Manuscript Podcast for convenient understanding

- Global attainment for your research

- Manuscript accessibility in different formats

( Pdf, E-pub, Full Text, Audio)

- Unceasing customer service

Track the below URL for one-step submission https://juniperpublishers.com/online-submission.php 